Revista de

Contabilidade e

Organizações

www.rco.usp.br
DOI: http://dx.doi.org/10.11606/rco.v10i26.79588
Journal of

Accounting and

Organizations

\title{
Análise do desempenho de alunos na perspectiva do "CHA" em disciplina utilizando PBL: o que significa a síntese?
}

\author{
Fábio Frezattia ; Márcio Luiz Borinellia; Daiana Bragueto Martins; ${ }^{\mathrm{a}}$, Márcia Maria dos Santos Bortolocci Espejo ${ }^{\mathrm{b}}$ \\ ${ }^{a}$ Universidade de São Paulo \\ ${ }^{b}$ Universidade Federal de Mato Grosso do Sul
}

\section{Informações do Artigo}

Histórico do Artigo

Recebido: 14 de abril de 2014

Aceito: 19 de dezembro de 2015

Palavras-chave:

Avaliação.

Problem-based learning.

Action research.

Ciências Contábeis.

Ciências Atuariais.

Competências.

\begin{abstract}
Resumo
Este artigo tem por objetivo atribuir significado ao conceito final obtido pelo aluno em disciplina ministrada sob a ótica do Problem-Based Learning, considerando a complexidade da perspectiva sinérgica do CHA (Conhecimentos, Habilidades e Atitudes). A estratégia metodológica tem por base o action research aplicado em uma turma noturna de alunos de graduação em Ciências Contábeis e Ciências Atuariais. O tratamento dos dados foi realizado por meio da análise de correlação e cluster, resultando na formação de três agrupamentos. Quanto aos achados, percebe-se que a combinação do CHA não pode ser simplesmente uma soma de elementos, mas sim, sinergicamente, um conjunto que proporciona condições de entender se o aluno, ao final do curso, teve o aprendizado planejado. É importante que o aluno entenda o que significa a nota global da disciplina, bem como as notas de cada elemento do CHA, para que perceba quais elementos devem ser reforçados. Dessa maneira, o feedback contínuo é vital durante todo o desenvolvimento do curso.
\end{abstract}

Copyright (C) 2016 FEA-RP/USP. Todos os direitos reservados

\section{INTRODUÇÃO}

A avaliação no processo educacional é algo de suma importância. Permite à instituição, ao aluno e ao docente dispor de parâmetros para seu posicionamento e ações futuras. Mais do que isso, possibilita à instituição se avaliar e, eventualmente, se reposicionar. A abordagem pode captar diferentes perspectivas, variando do enfoque "conhecimento adquirido" até chegar às "competências aperfeiçoadas". Contudo, ao mesclar o conjunto de instrumentos avaliativos, têm-se mecanismos para identificar o grau de conhecimento, especificamente falando-se (ANDERSON; KRATHWOHL, 2000) nas notas que despencam e a sensação de que algo está errado fica no ar.

Isso se torna mais relevante quando se trata de abordagens contemporâneas de ensino-aprendizagem, como o Problem-Based Learning (PBL), em que não apenas a dimensão do conhecimento é valorizada. Desta perspectiva surgem várias perguntas: Afinal, faz sentido notas altas em trabalhos coletivos e notas baixas em avaliações individuais? As notas coletivas estão superestimadas ou as notas individuais são subestimadas? Faz sentido somar notas de conhecimentos, habilidades e atitudes? Por que o PBL é empregado em uma ou outra disciplina apenas num conjunto de disciplinas tradicionais? Num ambiente competitivo e cooperativo, além de aprovar e reprovar, como entender os alunos de melhor desempenho e os de desempenho inferior? Qual e como proporcionar feedback que seja útil ao desenvolvimento do aluno? Como interpretar a nota e a aprovação de alunos ao final da disciplina? Na verdade, embora sejam inúmeras as perguntas, a questão de pesquisa que vai nortear este trabalho está baseada na última indagação.

Nesse sentido a motivação para o estudo foi a necessidade de olhar de uma maneira diferente para a avaliação de habilidades e atitudes assim como as suas consequências. Em outras palavras, ser reprovado por não ter conhecimento é parte da experiência e do contexto dos alunos, mas não existe essa experiência para habilidades e atitudes. Por ser algo desconhecido, tanto o risco de ser reprovado como também alguma expectativa de ninguém

Autor Correspondente: Tel (11) 3091-5820

E-mail: frezatti@usp.br (F. Frezatti); marciolb@usp.br (M. L. Borinelli); daianabm@hotmail.com (D. B. Martins);

marcia.bortolocci@ufms.br (M; M. S. B. Espejo)

Universidade de São Paulo - Av. Professor Luciano Gualberto, 908 - FEA 3 - Sala 232 - Butantã - CEP: 05508-900 - São Paulo - SP 
ser reprovado podem ser elementos que tomem a atenção dos alunos e impacte de maneira desfavorável sobre o desempenho escolar. Um passo além, fica a questão de que o conhecimento pode ser discutido em termos de utilidade na vida. E as habilidades e atitudes? Onde pode ser retomada a sua utilidade: na empresa, na vida em geral? Como consequência, o entendimento do que a avaliação representa, aqui tratado como "interpretação", tem amplitude decorrente da visão de contexto do participante e da oportunidade de exercitar em outro ambiente que não o da sala de aula.

Tendo em vista discutir os problemas identificados acima, a pesquisa de campo foi realizada com um grupo de estudantes de uma disciplina ministrada no primeiro semestre de 2013. A disciplina de contabilidade gerencial, optativa, voltada para alunos que já teriam sido expostos a conteúdos tais como: custos, análise de custos, planejamento estratégico e orçamento, e sistema de informações gerenciais. Foi estruturada de maneira que o grupo de estudantes pudesse ser acompanhado de maneira paulatina e consistente. A experiência foi desenvolvida junto a alunos, preponderantemente, do último ano dos cursos de graduação em Ciências Contábeis e Ciências Atuariais de uma instituição pública brasileira. Ela é a única disciplina da Faculdade a utilizar a abordagem do PBL. O fato de alunos de diferentes cursos (Atuária e Contábeis) conviverem numa mesma disciplina proporciona diferentes impactos. De um lado, uma heterogeneidade de conhecimentos adquiridos tanto no sentido educacional do curso como experiências profissionais, criando dificuldades em termos de temas comuns para discussão. Por outro lado, este fato gera oportunidades de integração. Destaca-se que um desafio relevante para alunos dos últimos semestres consiste em fazê-los trabalhar juntos sem instigação ou estímulo.

Ainda que a literatura trate as questões da avaliação nos cursos que aplicam PBL, as preocupações explicitadas dizem respeito muito mais sobre a técnica propriamente dita e não em relação à percepção que fica por parte dos alunos e dos professores sobre o que fizeram em termos de avaliação. A lacuna a ser tratada diz respeito ao aprendizado do aluno, já que a lógica do CHA (Conhecimentos, Habilidades e Atitudes) é apresentada de maneira segmentada quando, na verdade, tem uma enorme intersecção e, ao mesmo tempo, tem impactos recíprocos e sequenciais. Nesse sentido, busca-se a interação entre os elementos e o entendimento das influências de um dos elementos sobre os outros. Dessa maneira, como conviver com um sistema de avaliação tradicional que segmenta e atribui peso e, ao mesmo tempo, usar essa avaliação de forma coerente e consistente com a perspectiva do active learning?

Partindo do pressuposto de que o curso tem objetivos de aprendizagem estabelecidos, a visão holística será perseguida de maneira a entender os equilíbrios e desequilíbrios do CHA, levando em conta, ao mesmo tempo, um olhar individualizado e uma perspectiva do aluno como um todo. O referencial teórico (DALRYMPLE et al., 2007; BRODIE; GIBBINGS, 2009; UNGARETTI et al., 2015) indica que habilidades e atitudes podem ser consideradas de maneiras distintas no processo educacional e podem ser tratadas como elementos de avaliação ou podem simplesmente ser consideradas como demandantes de feedback, sem a inclusão no modelo que proporciona uma nota final. Desde que aceita a primeira abordagem, ou seja, a que considera que seja atribuída uma nota, como isso se apresenta no conjunto de outros elementos de avaliação?

Nesse sentido, se cada componente do CHA integra a nota (e não é apenas um feedback), e por mais que tais elementos sejam distintos, eles possuem uma atuação sinérgica, torna-se necessário compreender como cada elemento desses influencia/interfere na nota final e permite avaliar o verdadeiro desempenho do estudante. É nisso, portanto, que reside a problemática desta pesquisa. Para atender essa demanda, a questão de pesquisa que se apresenta é: Como analisar os elementos do CHA na composição da nota de alunos de uma disciplina baseada no PBL?

Assim sendo, esta pesquisa tem como objetivo atribuir significado ao conceito final obtido pelo aluno em disciplina ministrada sob a ótica do PBL, considerando a complexidade da perspectiva sinérgica do $\mathrm{CHA}$. A inovação desta pesquisa está justamente no questionamento do que se obtém de uma disciplina que aplica o PBL sendo avaliada por meio de uma perspectiva moldada na abordagem tradicional, visto que a avaliação deve respeitar as diretrizes institucionais que, via de regra, baseiam-se em estratégias de ensino tradicionais. As contribuições e implicações esperadas desta pesquisa se referem a trazer contribuições adicionais na utilização do PBL em seu momento de avaliação. Referem-se ao entendimento do ambiente de trabalho do PBL e, em especial, percepção sobre a adequação da abordagem atual de avaliação sobre: o conhecimento, as habilidades e as atitudes.

Mais especificamente, considera-se que os resultados desta pesquisa poderão contribuir para que as instituições de ensino discutam sobre as consequências de se mesclar disciplinas tradicionais e não tradicionais sobre a compreensão dos alunos. Ademais, a discussão, ao apresentar modelo que mescla na avaliação elementos considerados muito distintos na experiência dos alunos, permite compreender seus impactos e avaliar o quão relevante podem ser na formação do estudante.

Também se considera que a pesquisa contribui ao trazer discussão sobre tema relevante e pouco explorado 
no campo das ciências contábeis e ciências atuariais, além de colocar em prática novas abordagens de ensino nessas áreas do conhecimento, bem como instrumentos de avaliação que contemplem competências, habilidades e atitudes.

Por fim, considera-se a utilização da action research essencial para a captura de potencial de aperfeiçoamento do modelo, uma vez que o envolvimento dos pesquisadores desde o início do processo foi fundamental para entender em detalhes o comportamento dos estudantes frente à proposta de avaliação que foi realizada. Tem também o fato de que, em termos científicos, além de o trabalho potencialmente contribuir com estudos relativos ao PBL e ao CHA, a action research é uma estratégia pouco utilizada no campo da Contabilidade e Atuária.

Além desta introdução, o trabalho tem outras sete partes. No tópico 2 apresentam-se algumas pesquisas nacionais com a aplicação do PBL no ensino de Contabilidade e no 3 discute-se o processo de avaliação no PBL e as questões relativas à avaliação de competências. Já a seção 4 traz uma discussão sobre como avaliar competências. O tópico 5, por sua vez, descreve o design metodológico do trabalho. Na seção 6 apresentam-se as etapas do action research aplicadas no estudo e na 7 a análise dos resultados. $\mathrm{O}$ último tópico traz as considerações finais a que se chegou após o desenvolvimento da pesquisa.

\section{PBL NO ENSINO DE CONTABILIDADE}

O PBL tem forte aplicação em algumas áreas como a medicina; porém, nas ciências sociais aplicadas, principalmente, na contabilidade, ainda é incipiente. O Quadro 1 apresenta as pesquisas nacionais publicadas que discutem a aplicação do PBL no ensino contábil.

\begin{tabular}{|c|c|c|c|c|}
\hline Autores & Publicado em & Objetivo & Detalhes da Aplicação & Resultados \\
\hline $\begin{array}{l}\text { Rodrigues } \\
\text { \& Araújo } \\
(2007) .\end{array}$ & $\begin{array}{l}\text { Revista de } \\
\text { Educação }\end{array}$ & $\begin{array}{l}\text { Verificar se o método } \\
\text { PBL é aplicável } \\
\text { às disciplinas de } \\
\text { Contabilidade em uma } \\
\text { IES particular. }\end{array}$ & $\begin{array}{l}\text { A pesquisa empírica } \\
\text { ocorreu em dois grupos } \\
\text { de alunos, que foram } \\
\text { submetidos ao método } \\
\text { de ensino PBL. O } \\
\text { primeiro formado } \\
\text { por alunos do quarto } \\
\text { período na disciplina } \\
\text { Contabilidade Geral } \\
\text { e o segundo por } \\
\text { alunos do sexto } \\
\text { período na disciplina } \\
\text { de Contabilidade } \\
\text { Gerencial do curso de } \\
\text { Administração de uma } \\
\text { IES particular do estado } \\
\text { de São Paulo. }\end{array}$ & $\begin{array}{l}\text { Comprovaram a eficiência do } \\
\text { método e de sua aplicabilidade } \\
\text { às disciplinas e destacam } \\
\text { que devem ser observados } \\
\text { os recursos disponíveis e o } \\
\text { conteúdo básico a ser ensinado } \\
\text { previamente. }\end{array}$ \\
\hline $\begin{array}{l}\text { Siqueira, } \\
\text { Siqueira- } \\
\text { Batista, } \\
\text { Morch, R. B., } \\
\text { \& Siqueira- } \\
\text { Batista (2009) }\end{array}$ & $\begin{array}{l}\text { Contabilidade } \\
\text { Vista \& Revista }\end{array}$ & $\begin{array}{l}\text { Coletar e analisar a } \\
\text { percepção de alunos } \\
\text { de Contabilidade, } \\
\text { expostos ao processo } \\
\text { de aprendizagem por } \\
\text { meio do PBL, sobre a } \\
\text { aplicabilidade no método } \\
\text { na área contábil. }\end{array}$ & $\begin{array}{l}\text { Participaram quinze } \\
\text { alunos voluntários } \\
\text { da disciplina de } \\
\text { Contabilidade de } \\
\text { Custos II de uma } \\
\text { Instituição de Ensino } \\
\text { Superior pública. }\end{array}$ & $\begin{array}{l}\text { Dentre as opiniões coletadas } \\
\text { destacam-se: (i) a percepção } \\
\text { de que o método exige uma } \\
\text { postura muito mais atuante dos } \\
\text { discentes; (ii) foi perceptível } \\
\text { uma diferença no grau de } \\
\text { autonomia, por parte dos } \\
\text { estudantes, entre o método PBL } \\
\text { e o ensino tradicional; e (iii) o } \\
\text { surgimento de dúvidas quanto } \\
\text { à maior eficácia do método } \\
\text { no ensino da Contabilidade, } \\
\text { em relação à metodologia } \\
\text { tradicional. }\end{array}$ \\
\hline
\end{tabular}

Quadro 1. Pesquisas nacionais sobre o ensino contábil na perspectiva do PBL

Fonte: Elaboração Própria 


\begin{tabular}{|c|c|c|c|c|}
\hline Autores & Publicado em & Objetivo & Detalhes da Aplicação & Resultados \\
\hline $\begin{array}{l}\text { Soares, Araújo } \\
\text { \& Leal (2012) }\end{array}$ & $\begin{array}{l}\text { Capítulo do } \\
\text { Livro: Didática } \\
\text { para o ensino } \\
\text { nas áreas de } \\
\text { administração } \\
\text { e Ciências } \\
\text { Contábeis }\end{array}$ & $\begin{array}{l}\text { Avaliar a implementação } \\
\text { do Problem-based } \\
\text { Learning - PBL como } \\
\text { metodologia de ensino- } \\
\text { aprendizagem no curso } \\
\text { de Ciências Contábeis. }\end{array}$ & $\begin{array}{l}\text { A aplicação do } \\
\text { método PBL foi } \\
\text { realizada na disciplina } \\
\text { Contabilidade } \\
\text { Intermediária I do } \\
\text { Curso de Ciências } \\
\text { Contábeis, no tópico } \\
\text { Operações com } \\
\text { Mercadorias. }\end{array}$ & $\begin{array}{l}\text { Os resultados apontam a } \\
\text { aderência ao PBL, no qual os } \\
\text { estudantes buscaram cumprir } \\
\text { as etapas e princípios sugeridos } \\
\text { pelo método. O conhecimento } \\
\text { proposto foi alcançado } \\
\text { satisfatoriamente pelos } \\
\text { estudantes que demonstraram } \\
\text { aceitabilidade à aplicação } \\
\text { do método PBL, o qual } \\
\text { possibilitou o desenvolvimento } \\
\text { de habilidades para a resolução } \\
\text { de problemas e comunicação. }\end{array}$ \\
\hline $\begin{array}{l}\text { Frezatti e } \\
\text { Silva (2014) }\end{array}$ & $\begin{array}{l}\text { Revista Universo } \\
\text { Contábil }\end{array}$ & $\begin{array}{l}\text { Discutir, dentro das } \\
\text { perspectivas do método } \\
\text { PBL, estratégias para } \\
\text { manter o interesse dos } \\
\text { estudantes perante } \\
\text { a disciplina, face à } \\
\text { prática versus incerteza. }\end{array}$ & $\begin{array}{l}\text { A disciplina } \\
\text { utilizada foi criada } \\
\text { especialmente para } \\
\text { a implementação do } \\
\text { método PBL. O tema } \\
\text { norteador escolhido foi: } \\
\text { impactos do sistema de } \\
\text { informações gerenciais } \\
\text { sobre o gerenciamento } \\
\text { das organizações. Esse } \\
\text { tema foi escolhido, pois } \\
\text { permite aos estudantes } \\
\text { do Curso de Ciências } \\
\text { Contábeis identificarem } \\
\text { uma vasta gama de } \\
\text { oportunidades dentro } \\
\text { das organizações. }\end{array}$ & $\begin{array}{l}\text { Apresentam oito ingredientes- } \\
\text { chave para o sucesso } \\
\text { na disciplina: o leilão } \\
\text { de problemas; o critério } \\
\text { de definição do líder; o } \\
\text { processo de "alocação" de } \\
\text { participantes; expansão e } \\
\text { redução no tratamento do } \\
\text { problema; escolha da empresa } \\
\text { pela acessibilidade aos } \\
\text { dados; clareza das normas } \\
\text { de formatação e estrutura } \\
\text { do projeto e relatório final; } \\
\text { formas de acesso e estímulo } \\
\text { à literatura; aulas expositivas } \\
\text { para direcionamento e reforço } \\
\text { das atividades; check-list das } \\
\text { atividades das sessões tutoriais; } \\
\text { e feedback das socializações, } \\
\text { autoavaliação do processo e de } \\
\text { aprendizagem. }\end{array}$ \\
\hline $\begin{array}{l}\text { Martins e } \\
\text { Espejo (2015) }\end{array}$ & $\begin{array}{l}\text { Livro : Problem } \\
\text { Based Learning- } \\
\text { PBL no Ensino } \\
\text { de Contabilidade: } \\
\text { guia orientativo } \\
\text { para professores } \\
\text { e estudantes da } \\
\text { nova geração. }\end{array}$ & $\begin{array}{l}\text { Apresenta uma reflexão } \\
\text { sobre o PBL e o ensino } \\
\text { de contabilidade ao } \\
\text { discutir o ensino da nova } \\
\text { geração de contadores, } \\
\text { os elementos essenciais } \\
\text { do PBL, o processo } \\
\text { avaliativo das disciplinas } \\
\text { que contemplam } \\
\text { a avaliação de } \\
\text { competências no PBL e } \\
\text { os relatos de experiências } \\
\text { com o PBL. }\end{array}$ & $\begin{array}{l}\text { Contempla duas } \\
\text { experiências em PBL } \\
\text { no ensino superior } \\
\text { de contabilidade, } \\
\text { ambas ocorridas na } \\
\text { Universidade de São } \\
\text { Paulo (FEA/USP e } \\
\text { FEA/RP). }\end{array}$ & $\begin{array}{l}\text { Apresenta um guia orientativo } \\
\text { para que o PBL seja aplicado } \\
\text { em outras disciplinas e em } \\
\text { outras IES, especialmente, no } \\
\text { curso de Ciências Contábeis. }\end{array}$ \\
\hline
\end{tabular}

Quadro 1 (continuação) Pesquisas nacionais sobre o ensino contábil na perspectiva do PBL

Fonte: Elaboração Própria

Cabe destacar que no Brasil os estudos que abarcam a abordagem do PBL expandiram a partir do século XXI, não apenas na contabilidade, mas em diversas áreas do conhecimento. Desta feita, nota-se que não há trabalhos que discutem o processo avaliativo e o feedback ao ensinar contabilidade com abordagem em PBL. 


\section{PROCESSO DE AVALIAÇ̃̃O NO PBL}

A aprendizagem é vista de forma holística no PBL, ou seja, entende-se um problema na sua totalidade a partir do entendimento das partes e suas inter-relações. Assim, avalia-se a capacidade dos alunos para atuar em um contexto profissional, reconhecendo suas necessidades de adquirir novos conhecimentos, habilidades e atitudes (DESAULNIERS, 1997). O PBL permite formar futuros profissionais aptos a construírem seu próprio conhecimento e a desenvolverem habilidades e atitudes ao trabalharem em equipe de modo articulado e fecundo, de tal forma que a estruturação do processo de avaliação permite um sistema de ensino-aprendizagem contínuo (SIQUEIRA-BATISTA; SIQUEIRA-BATISTA, 2009).

Para eliminar (ou reduzir) a ambiguidade na avaliação é recomendável observar as práticas apresentadas por Woods (2000, p. 7), isto é, os objetivos, os critérios, os instrumentos, os recursos e o processo avaliativo. Marks-Maran e Thomas (2000) afirmam que um sistema de avaliação baseado em problemas deve, portanto, ser projetado para medir os seguintes aspectos do desempenho dos alunos: (i) o conteúdo do curso; (ii) a habilidade de utilizar o conhecimento adequado para resolver problemas da vida real; (iii) a capacidade de fornecer evidências que justificam as decisões que foram tomadas; (iv) avaliar a análise de uma situação crítica; (v) a síntese das diversas fontes pesquisas; e (vi) a decisão tomada pelos alunos. Além disso, ressaltam a importância de, no PBL, avaliar a capacidade dos alunos de trabalhar de forma independente e em cooperação com os elementos de um grupo.

Desta feita, observa-se que o PBL auxilia no desenvolvimento das competências e corrobora com o desenvolvimento dos elementos apontados na Taxonomia de Bloom no tocante ao domínio cognitivo, o qual está

[...] relacionado ao aprender, dominar um conhecimento. Envolve a aquisição de um novo conhecimento, do desenvolvimento intelectual, de habilidade e de atitudes. Inclui reconhecimento de fatos específicos, procedimentos padrões e conceitos que estimulam o desenvolvimento intelectual constantemente (FERRAZ; BELHOT, 2010, p. 422).

Neste domínio, Bloom et al. (1983) agruparam os objetivos educacionais em seis categorias, a saber: (i) conhecimento, (ii) compreensão, (iii) aplicação, (iv) análise, (v) síntese e (vi) avaliação. Há uma hierarquia de complexidade e dependência entre as categorias, sendo o primeiro nível a mais simples (conhecimento) e o último a mais complexa (avaliação). Para transpor um degrau, é necessário que o aluno tenha obtido um desempenho adequado no anterior, pois cada categoria utiliza as capacidades já adquiridas nos níveis anteriores (FERRAZ; BELHOT, 2010).

No PBL utiliza-se de uma variedade de métodos de avaliação, no decorrer do processo de ensinoaprendizagem (da disciplina, do semestre ou do curso). A qualidade do feedback no PBL irá melhorar ao envolver diferentes instrumentos de avaliação, bem como a utilização da autoavaliação e da avaliação pelos pares, e diferentes avaliadores (professor, aluno e colegas). Além disso, a avaliação engloba técnicas e instrumentos que podem ser modificados e adaptados de outras abordagens; porém, o importante é garantir um equilíbrio entre o programa (objetivos educacionais), variedades de instrumentos e tempo de avaliação (MACDONALD; SAVINBADEN, 2004; SIQUEIRA-BATISTA; SIQUEIRA-BATISTA, 2009).

Na pesquisa realizada por MacDonald e Savin-Baden (2004) encontram-se os principais instrumentos de avaliação utilizados no PBL, a saber: apresentação em grupo, apresentação individual, tripartida (tríplice), trabalhos individuais baseados em casos, projeto baseados em casos práticos para o cliente, portfólio/pasta, salto triplo, autoavaliação, avaliação pelos pares, exames por viva voz (exames orais), diários ou journals reflexivos (online), avaliação do tutor/facilitador, relatórios, entre outros instrumentos.

\section{AVALIAR COMPETÊNCIAS}

Therrien e Loiola $(2001,154)$ afirmam que "[...] ser competente é ser capaz de utilizar e de aplicar procedimentos práticos apropriados em uma situação de trabalho concreta". Na visão de Brandão (2009), os processos cognitivos ou a aquisição de conhecimento, de habilidades e de atitudes são oriundos da inserção e interação do indivíduo no meio social. Desta forma, a competência pode ser definida como desempenho profissional 
ou social expressa pelo sujeito, de seus conhecimentos, suas habilidades e suas atitudes, em um contexto específico (BRANDÃO, 2009).

Nesta perspectiva, a avaliação dos conhecimentos contempla os saberes teóricos e práticos adquiridos. No tocante as habilidades, afere-se a capacidade dos estudantes de resgatarem e utilizarem seus conhecimentos prévios sobre o tema da disciplina, seus conhecimentos de mundo e suas experiências de vida, bem como as técnicas utilizadas para solucionar um problema atual (BLOOM et al., 1983). Avaliar a forma como é realizada uma determinada tarefa, significa avaliar as atitudes dos discentes na disciplina. Está relacionada ao comportamento do estudante em relação aos demais colegas e a uma determinada situação (BRANDÃO, 2009).

Assim, pode-se perceber a potencialidade do PBL integrando conhecimentos obtidos durante uma dada disciplina ou mesmo durante toda a vida. O papel do grupo, nesse caso, se constitui num elemento que permite ao aluno aprender, lembrar, resgatar conhecimentos anteriormente tratados, aplicá-los e a assumir um comportamento em relação aos demais colegas para solucionar o problema proposto. Segundo Desaulniers (1997), a competência é inseparável da ação, e os conhecimentos teóricos são utilizados de acordo com a capacidade de executar as decisões que ela (a ação) sugere. A competência se constrói, portanto, na articulação entre um saber e um contexto; além disso, o profissional é capaz de transpor a aprendizagem para outros contextos. Assim, ser competente é: a) saber agir com competência; b) saber mobilizar saberes e conhecimentos em um contexto profissional; c) saber integrar ou combinar saberes múltiplos e heterogêneos; d) saber transpor; e) saber aprender e aprender a saber; e f) saber envolver-se. O profissionalismo e a competência resultam não somente de um saber agir, mas de um querer agir e de um poder agir; e, associados à competência, estão os aspectos cognitivos, afetivos e sociais inerentes à motivação humana (LE BOTERF, 2000).

Avaliar competência “[...] não se trata de avaliar o indivíduo, mas seu agir profissional em um determinado contexto" (ROSA; CORTIVO; GODOI, 2006, p. 82). Com base nesta proposta, o processo avaliativo da disciplina alvo desta pesquisa foi estruturado com base no Quadro 2, que contempla a avaliação dos conhecimentos, das habilidades e das atitudes.

\begin{tabular}{|c|c|c|c|}
\hline Competências & Elementos avaliados & Autores & $\begin{array}{l}\text { Instrumentos de } \\
\text { avaliação }\end{array}$ \\
\hline \multirow{4}{*}{ Conhecimento } & $\begin{array}{l}\text { Domínio da bibliografia } \\
\text { referente ao problema. }\end{array}$ & Woods (2006); Frezatti et al (2009). & \multirow{4}{*}{$\begin{array}{l}\text { - Prova escrita } \\
\text { individual; } \\
\text { - Apresentação em grupo } \\
\text { dos resultados parciais e } \\
\text { finais; e } \\
\text { - Relatórios de progresso } \\
\text { parcial e final; }\end{array}$} \\
\hline & $\begin{array}{l}\text { Conhecimento } \\
\text { profissional. }\end{array}$ & Vasconcelos, Cavalcante e Monte (2011). & \\
\hline & Ferramentas de pesquisa. & Silva (2008); Porton e Beuren (2008). & \\
\hline & Metodologia científica. & Marconi e Lakatos (2003); Yin (2001). & \\
\hline \multirow{13}{*}{ Habilidades } & Trabalho em equipe. & Ribeiro (2010). & \multirow{13}{*}{$\begin{array}{l}\text { - Autoavaliação; e } \\
\text { - Avaliação pelos pares. }\end{array}$} \\
\hline & Criatividade e inovação. & Enemark e Kjaerdam (2009). & \\
\hline & Visão sistêmica. & Vasconcelos, Cavalcante e Monte (2011). & \\
\hline & Comunicação. & $\begin{array}{l}\text { Chaves et al. (2006); Enemark e Kjaerdam } \\
\text { (2009). }\end{array}$ & \\
\hline & Planejamento. & Schmidt (1983). & \\
\hline & $\begin{array}{l}\text { Integração com a } \\
\text { empresa. }\end{array}$ & Enemark e Kjaerdam (2009). & \\
\hline & $\begin{array}{l}\text { Integração com outras } \\
\text { disciplinas. }\end{array}$ & Savery (2006); Enemark e Kjaerdam (2009). & \\
\hline & $\begin{array}{l}\text { Desenvolvimento de } \\
\text { projetos. }\end{array}$ & Enemark e Kjaerdam (2009). & \\
\hline & Análise crítica. & $\begin{array}{l}\text { Des Marchais (1999); Duch (2001); Chaves et } \\
\text { al.(2006). }\end{array}$ & \\
\hline & Solução de problema. & Chaves et al (2006); Ribeiro (2010). & \\
\hline & Autoavaliação. & Chaves et al. (2006). & \\
\hline & Estudo independente. & Chaves et al (2006); Ribeiro (2010). & \\
\hline & Trabalho autorregulado. & Savery (2006); Ribeiro (2010). & \\
\hline
\end{tabular}

Quadro 2. Avaliação das Competências no PBL

Fonte: Elaboração Própria 


\begin{tabular}{|c|c|c|c|}
\hline Competências & Elementos avaliados & Autores & $\begin{array}{l}\text { Instrumentos de } \\
\text { avaliação }\end{array}$ \\
\hline \multirow{11}{*}{ Atitudes } & Comprometimento. & $\begin{array}{l}\text { Chaves et al.(2006); Vasconcelos, Cavalcante } \\
\text { e Monte (2011). }\end{array}$ & \multirow{11}{*}{$\begin{array}{l}\text { - Autoavaliação; e } \\
\text { - Avaliação pelos pares. }\end{array}$} \\
\hline & Ética. & Woods (2006). & \\
\hline & Pró atividade. & Woods (2006). & \\
\hline & Empatia. & Vasconcelos, Cavalcante e Monte (2011). & \\
\hline & Flexibilidade. & Vasconcelos, Cavalcante e Monte (2011). & \\
\hline & Interesse. & Duch (2001); Araújo e Arantes (2009). & \\
\hline & Curiosidade. & Des Marchais (1999). & \\
\hline & Experiência profissional & Ribeiro (2010). & \\
\hline & $\begin{array}{l}\text { Respeito pelas opiniões } \\
\text { de outros. }\end{array}$ & Ribeiro (2010). & \\
\hline & $\begin{array}{l}\text { Colaboração e } \\
\text { cooperação. }\end{array}$ & Savery (2006). & \\
\hline & Liderança. & Manaf, Ishak e Hussin (2011). & \\
\hline
\end{tabular}

Quadro 2 (continuação) Avaliação das Competências no PBL

Fonte: Elaboração Própria

\section{DESIGN METODOLÓGICO}

Para atender ao objetivo da pesquisa e responder à questão proposta, realizou-se uma pesquisa exploratória que ocorreu por meio da abordagem metodológica do action research (COUGHLAN; COUGHLAN, 2002), cujo objetivo foi analisar o processo avaliativo da disciplina baseada em PBL. A pesquisa de campo ocorreu em uma disciplina de 32 horas-aula, ou seja, 16 encontros presenciais com os estudantes. As aulas foram divididas em cinco esferas: aulas híbridas (expositivas e trabalho em equipe); sessões tutoriais; socializações dos resultados; prova; e autoavaliação e avaliação pelos pares. Os detalhes do desenvolvimento da disciplina encontram-se na seção seguinte.

A action research é considerada como um "trabalho em processo" (WRIGHT; SMITH; DUNCAN, 2011). Para Mettetal (2001, p. 108), a action research em sala de aula "[...] é a investigação sistemática sobre o que funciona na sala de aula, com o objetivo de melhorar a aprendizagem dos alunos". Os autores Wright, Smith e Duncan (2011) afirmam que é satisfatória na aplicação em pesquisas no ensino com abordagem do PBL, pois reconhece que as pessoas aprendem de maneiras diferentes o que permite aos alunos realizarem escolhas sobre o direcionamento de sua própria aprendizagem. Com base nisso, as ferramentas utilizadas para realizar esta pesquisa foram (i) os intrumentos avaliativos realizados pelos alunos e (ii) os relatórios de observação dos docentes. Ademais, conforme apresentado por Coughlan e Coughlan (2002), a abordagem da action research permite visualizar a relação entre o planejamento da atividade e a execução, conforme ilustra a Figura 1.

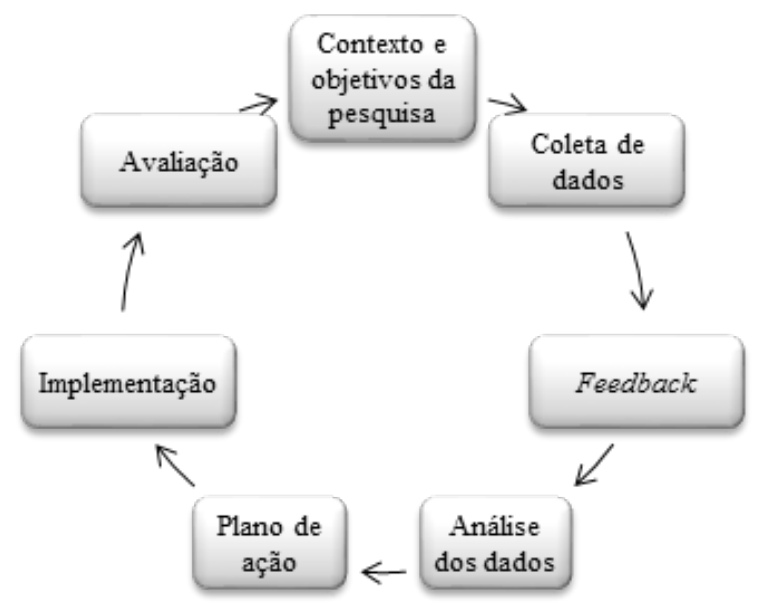

Figura 1. Ciclos da action research (Coughlan e Coughlan, 2002) 
A Figura 1 evidencia o ciclo de atividades desenvolvidas na action research, a saber: (i) esclarecimento sobre os objetivos e o contexto da pesquisa; (ii) obtenção de dados sobe os envolvidos no processo, neste caso os alunos; (iii) feedback para os envolvidos (alunos) sobre os dados obtidos; (iv) análise dos dados; (v) plano de ação; (vi) implementação; e (vii) avaliação. Ao final, um novo ciclo inicia-se.

\section{DESENVOLVIMENTO DA ACTION RESEARCH EM UMA ABORDAGEM DE PBL}

Com base no modelo proposto por Coughlan e Coughlan (2002), as etapas da action research foram assim observadas nesta pesquisa:

\subsection{Esclarecimento sobre os objetivos e contexto da pesquisa:}

A disciplina contou com a direção de dois docentes da escola, de auxílio tutorial permanente de uma professora colaboradora externa à instituição, e com a participação de uma professora visitante no planejamento da disciplina. A equipe discutiu todo o programa previamente e, com o transcorrer da disciplina, ajustou e coordenou as atividades, utilizando-se de reuniões semanais extraclasses.

Antes do início das aulas, realizou-se um contato via e-mail com os alunos matriculados na disciplina com intuito de explicar as diferenças da metodologia de ensino tradicional e do PBL, bem como esclarecer alguns objetivos de aprendizagem. Solicitou-se aos estudantes que preenchessem o questionário da avaliação diagnóstica que foi disponibilizado online cujo objetivo foi proporcionar entendimento do conhecimento prévio.

Na primeira aula, apresentou-se aos participantes da disciplina o programa, a justificativa do uso do método PBL, os objetivos da disciplina, o cronograma de atividades a serem desenvolvidas no decorrer do semestre, bem como foram expostas as competências a serem construídas na disciplina e seus instrumentos de avaliação (Quadro 2).

\subsection{Obtenção de dados sobre os envolvidos no processo (discentes):}

Dos 43 estudantes matriculados na disciplina, 38 concluíram e destes 24 realizaram a avaliação diagnóstica, representando $63 \%$ do grupo. A avaliação diagnóstica contemplou um questionário que foi disponibilizado online pela plataforma do "formsite". O mesmo possui três blocos de questões: o primeiro contemplou o perfil dos estudantes; o segundo, as expectativas no tocante à disciplina e aos professores; e o terceiro sobre conhecimentos diretamente relacionados à ementa da disciplina. Destaca-se que a realização desta avaliação era facultativa para o aluno, pois a mesma não estava atrelada à composição da nota do discente para ser aprovado ou não nesta disciplina.

Com relação às variáveis demográficas, destaca-se que a maioria dos discentes que cursaram a disciplina possui no máximo 25 anos e apenas 3\% dos respondentes possuem mais de 35 anos. Neste grupo de estudantes, $82 \%$ estão empregados ou estagiando e, destes, $50 \%$ são analistas, $32 \%$ estagiários, $9 \%$ gerentes, $6 \%$ empresários (sócios) e 3\% supervisores.

A experiência profissional existente é um fator que, ao mesmo tempo, demanda liberdade contextual e tem um rico campo para trazer a realidade para a sala de aula. A disciplina, que é optativa, contou com a participação efetiva de 18 alunos de Ciências Atuariais e 20 de Ciências Contábeis, formando 7 grupos de trabalho. Observouse uma significativa preocupação dos discentes no tocante ao elemento conhecimento e os mesmos apresentaram o docente como o detentor do conhecimento, ou seja, aquele que ministra aulas com objetivo de transmitir o conhecimento (o foco na abordagem tradicional). Vários estudantes destacaram que a expectativa deles em relação aos docentes era que os mesmos: "dominem os conteúdos curriculares das disciplinas", "passem o conhecimento teórico e prático da área" e "que abordem o conteúdo com boa didática e de forma esclarecedora". Portanto, embora tendo tomado conhecimento da abordagem do PBL, a expectativa em termos de papéis não havia se alterado em relação às abordagens tradicionais. 
6.3 Feedback para os envolvidos (discentes) sobre os dados obtidos:

No decorrer da disciplina houve vários momentos em que o discente recebeu feedback individual e/ou do grupo sobre as atividades e as avaliações realizadas. O feedback da avaliação diagnóstica e dos problemas escolhidos ocorreu na terceira aula, pois neste momento o aluno já possuía uma prévia do problema, a justificativa do estudo e seu contexto.

$\mathrm{Na}$ aula após a prova (única na disciplina), isto é, na décima primeira aula, na qual ocorreu uma sessão tutorial, os alunos receberam, via ambiente virtual de aprendizagem, o relatório parcial com as observações, as correções e as sugestões realizadas pelos docentes, bem como o relatório detalhado com as notas da avaliação do relatório parcial e da socialização dos resultados parciais da pesquisa para resolução do problema proposto para cada grupo. Já o feedback da prova de conteúdo ocorreu na décima terceira aula, última sessão tutorial. As notas e o relatório com as correções, sugestões e apontamentos realizados pelos docentes referentes à socialização e ao relatório final foram divulgados duas semanas após o término das aulas por meio do ambiente virtual de aprendizagem, sendo que a mesma foi composta pela média atribuída pelas notas de três docentes.

\subsection{Análise dos dados:}

Tendo em vista que esta foi a primeira experiência da turma com aulas em PBL, verificou-se como item de maior dificuldade para o aluno o ato de encontrar um problema em sua realidade empresarial. Vale ressaltar que na aula da legitimação dos problemas (quinta aula) apenas o grupo 2 (de um total de 7) estava mais avançado na elaboração do projeto. Os demais grupos precisavam acertar ora o problema ora o contexto e/ou as hipóteses.

Nas avaliações dos relatórios e das socializações dos resultados parciais apresentados pelos grupos, a média da turma ficou em 5,6 com máximo de 7,2 e mínimo de 3,7. A nota obtida nestas avaliações foi composta pela média das notas dos três professores. Os grupos 5 e 6 apresentaram nota superior a 6, os grupos 1, 4 e 7 ficaram com 5,6, 5,8 e 5,6 respectivamente e os grupos 2 e 3 com notas inferiores a 5. Observou-se nesta avaliação o conhecimento que o aluno apresentou por meio da sua comunicação oral e escrita de pelo menos um dos conteúdos contidos no tema da disciplina e o seu vínculo com o problema exposto. Além disso, avaliou-se, por meio da pesquisa realizada, a presença das habilidades a seguir: o trabalho autorregulado, o estudo independente, a integração com a empresa e com outras disciplinas.

Na prova escrita e individual, que abordou elementos constitutivos apenas de conhecimento, observou-se média de 6,0 pontos e valor mínimo maior do que o apresentado na avaliação diagnóstica (que também abordou conhecimento). Isso significou melhoria dos conhecimentos adquiridos pelos alunos, percebida por meio de uma avaliação com questões abertas e fechadas. Na escala apresentada por Bloom et al. (1983), a prova aplicada consegue captar o degrau da compreensão.

Ainda no tocante às avaliações dos discentes, observou um melhor desempenho na socialização e no relatório final (média de 7,2 e 6,6, ambos com desvio-padrão baixo de 1,5 e 1,1, respectivamente) em relação ao relatório parcial; sendo a nota máxima na apresentação (socialização) de 9,0 e a mínima de 3,0, com destaque para três alunos que estavam presentes na data da socialização de seus grupos, porém não apresentaram; no relatório final a maior nota foi 7,9 e a mínima de 4,5. Nota-se que estes instrumentos avaliativos conseguiram captar na escala apresentada por Bloom et al. (1983) o nível da síntese, porém são captados pelo trabalho em equipe e não individualmente para cada estudante.

Observa-se que as notas atribuídas para as atitudes foram superiores tanto às habilidades quanto aos conhecimentos, uma vez que neste quesito a média da turma ficou em 8,0 pontos, as habilidades com 7,6 pontos e os conhecimentos com 6,3 pontos. A avaliação que foi atribuída a maior média foi à avaliação pelos pares para as atitudes com 8,1 pontos na média, sendo que o desvio-padrão baixo de 1,1 representa homogeneidade.

Assim, destaca-se que para avaliar a competência no PBL utilizaram-se nesta disciplina cinco diferentes instrumentos avaliativos. Constata-se que dos 38 alunos concluintes o elemento menos desenvolvido na disciplina foi o conhecimento com $13 \%$ dos discentes com nota média inferior a 5,0 pontos e 14 alunos apresentaram nota média superior a 7,0 pontos. O conhecimento, conforme apresentado no Quadro 2, foi avaliado pelo relatório parcial e final, a socialização de resultado parcial e final e pela prova individual de conhecimentos, sendo avaliados nesta última os temas a seguir: PBL, Action Research e os elementos constitutivos do tema da disciplina. 
As habilidades e as atitudes foram avaliadas por dois instrumentos, a saber: a autoavaliação e a avaliação pelos pares. Constatou-se que aproximadamente $60 \%$ dos alunos ficaram com nota superior a 7 e inferior a 8 no quesito habilidade, com nenhum aluno com média inferior a 5,5. Observa-se que o quesito atitude foi o melhor avaliado, sendo que aproximadamente $75 \%$ dos alunos receberam nota média superior a 7,0 pontos e, destes, $68 \%$ apresentaram nota média superior a 8,0; por outro lado, um aluno apresentou nota média inferior a 6,0 pontos. Cabe destacar que tanto a autoavaliação quanto a avaliação pelos pares conseguiram mensurar um valor para as habilidades e para as atitudes, os quais atingiram o nível de maior complexidade apresentado por Bloom et al. (1983), qual seja a avaliação.

Como se pode perceber, além do action research para proporcionar a estruturação da pesquisa, esforço planejado no gerenciamento das aulas e o feedback são necessários, inclusive para que o docente e o aluno percebam justiça no desenvolvimento da disciplina.

\subsection{Plano de ação:}

A disciplina optativa com a abordagem de PBL teve por objetivo identificar, analisar e propor soluções para problemas emergentes das empresas brasileiras, no que se refere ao campo do controle gerencial. Os processos acadêmicos de resolução de problemas da disciplina no primeiro semestre de 2013 envolvem grupos de estudantes que atuaram da seguinte maneira:

Identificando problemas na realidade científica e cotidiana; discutindo um problema particular; utilizando seus próprios conhecimentos e experiências, com o auxílio de professores e outros meios, na busca de respostas para o problema abordado; levantando uma série de hipóteses que podem explicar e resolver o problema; procurando investigar as hipóteses apontadas e apontar possíveis respostas e/ou soluções; e no final do processo, preparando um relatório acadêmico contendo reflexões teóricas e análises sobre o problema estudado e socializando os resultados do projeto desenvolvido como o coletivo da classe (ARAÚJO; ARANTES, 2009, p.107).

Desta feita, o processo de operacionalização da disciplina ocorreu conforme a Figura 2.

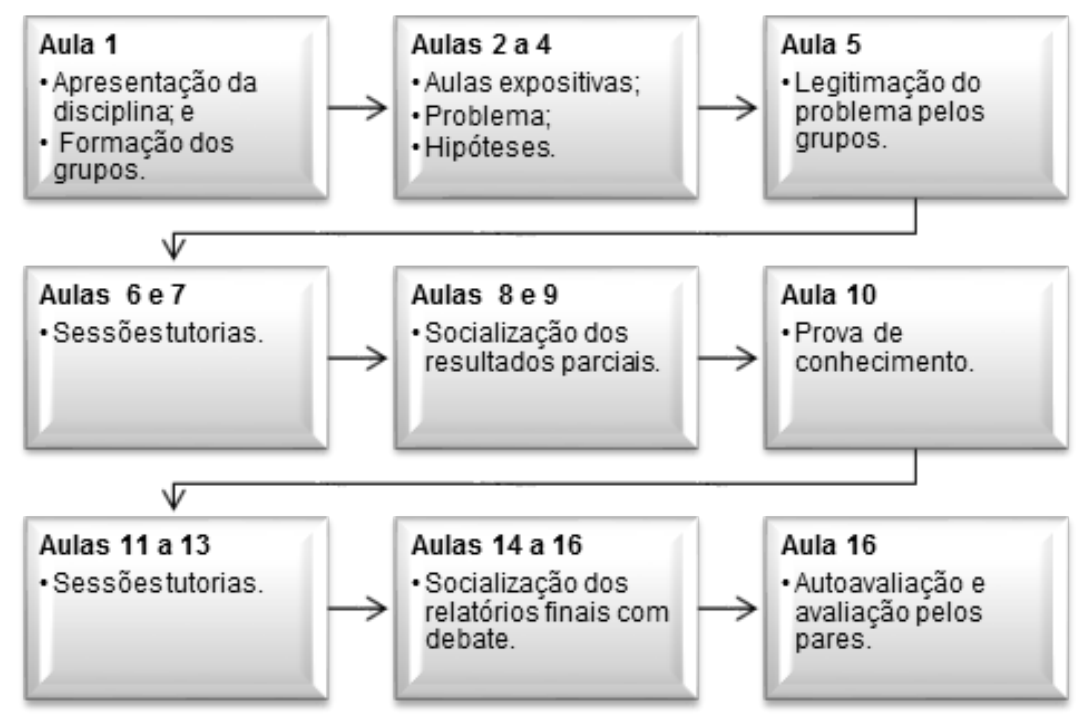

Figura 2. Operacionalização da disciplina na distribuição das aulas

Após escolhido o problema, os grupos trabalharam na estruturação do projeto, pois a disciplina trabalha com apenas um problema por grupo durante todo o semestre. Nesta modalidade, os alunos apresentaram forte integração com pelo menos uma área de conhecimento. $\mathrm{O}$ trabalho em grupo foi desenvolvido tanto em sala de aula como em reuniões extraclasses e os professores forneceram pouca referência (RIBEIRO, 2010).

As aulas 2 a 4 dividiram-se em duas partes, sendo a primeira destinada às interferências dos docentes responsáveis pela disciplina para transmitir informações sobre o PBL, o tema da disciplina e os aspectos operacionais do método PBL aplicado ao controle gerencial. Na segunda parte das aulas, os alunos reuniram os 
respectivos grupos e trabalharam para melhor delimitar o problema estudado e elencar as principais preposições a serem investigadas na literatura. Na sequência, realizou-se a legitimação dos problemas (aula 5); nesta aula, os alunos definiram perante a classe o problema que cada grupo abordou, sendo aberta a possibilidade de troca de membros por afinidade com o problema, porém os grupos de mantiveram conforme estavam.

Nas sessões tutoriais (aulas 6 a 7 e 11 a 13), os docentes atuaram como facilitadores e tutores dos diversos grupos formados pelo total de estudantes que cursam a disciplina. Eles intervieram mais no processo de solução dos problemas de modo a esclarecer conceitos equivocados para todos os alunos, interagiram sintetizando o conhecimento construído até o momento e buscaram alavancar os grupos deficitários ao estágio em que a maioria dos grupos se encontrava (RIBEIRO, 2010).

Optou-se por realizar a prova de conteúdo (aula 10) logo após a socialização dos resultados parciais (aulas 8 e 9). Assim o aluno poderia refletir melhor sobre o seu processo de aprendizagem e se esforçar para desenvolver outras competências, que não fosse apenas o conteúdo, a saber: as habilidades e as atitudes.

As socializações dos grupos para apresentar o resultado final, foram complementadas pelo debate com a classe (aulas 14 a 16), ou seja, houve um espaço para ouvir as contribuições e/ou dúvidas dos demais colegas da classe. Por fim, realizou-se a autoavaliação, a avaliação pelos pares e a avaliação da disciplina sob a perspectiva do aluno (aula 16). Conforme apresentado no Quadro 2, os alunos avaliaram atribuindo nota de 0 a 10 a si mesmo e aos membros do grupo para cada elemento constitutivo das habilidades e das atitudes desenvolvidas nesta disciplina com a abordagem do PBL. O formulário utilizado para autoavaliação e avaliação pelos pares encontrase anexo a este texto.

\subsection{Implementação:}

As implementações aconteceram constantemente na disciplina, tendo em vista que o grupo de professores se reuniu todas as segundas-feiras no período vespertino para discutir questões referentes ao andamento da disciplina, às atitudes dos alunos no que se refere à presença e participação, aos pontos positivos e negativos da aula anterior, com intuito de aperfeiçoar a aula a ser ministrada no período noturno. Os docentes visavam sanar nas aulas as principais dificuldades apresentadas pelos alunos nas atividades realizadas tanto em sala quanto extraclasse.

Algumas reações eram esperadas dos grupos como, por exemplo, a ausência nas reuniões tutoriais. Assim, na segunda rodada de sessões tutoriais, que aconteceu nas aulas 11, 12 e 13, os professores realizaram um controle mais rigoroso de participação.

Após a entrega do relatório parcial e da socialização dos resultados parciais dos grupos, verificou-se a necessidade de acrescentar uma aula expositiva sobre metodologia científica com foco em estudo de caso, pois se observou uma deficiência por parte dos grupos neste quesito. Esperava-se dos alunos a aplicação dos conhecimentos de metodologia científica, ou seja, era tido como conhecimento prévio já adquirido pelo aluno, proporcionando a interdisciplinaridade entre as disciplinas, uma vez que há a disciplina obrigatória na matriz curricular de ambos os cursos.

\subsection{Avaliação:}

Ao final da disciplina, depois de terminado o curso, a última atividade da aula 16, mas antes de serem divulgadas as notas, os alunos realizaram a avaliação do curso e da metodologia instrucional atribuindo nota de 0 a 10 para cada atributo (aulas expositivas, um problema por grupo, o trabalho em grupo, as sessões tutoriais, os relatórios e o processo avaliativo adotado). O formulário utilizado para a avaliação da disciplina encontra-se anexo a este texto.

O feedback desta avaliação permitiu identificar que o elemento melhor avaliado foi o papel dos professores com média de 9,42 pontos, seguido do trabalho com problema $(9,36)$ e das sessões tutoriais $(9,14)$. Embora os itens referentes a futuras experiências com o PBL apresentaram média 9,11 e 8,78, um estudante respondeu que não possui intenção de trabalhar novamente com essa abordagem ao atribuir nota zero e três ficaram indecisos ao avaliarem com notas entre 4 e 6 . 


\section{ANÁLISE DOS RESULTADOS}

O conjunto de elementos da avaliação foi estruturado para conter componentes que permitissem o desenvolvimento do trabalho e, ao mesmo tempo, não distorcesse a visão de desempenho da lógica do projeto político-pedagógico da instituição. Dessa maneira, o peso das habilidades e das atitudes no modelo de avaliação não foi muito agressivo, conforme evidência o Quadro 3. Contudo, apesar da discreta contemplação das habilidades e atitudes, o modelo avaliativo supera a abordagem tradicional por considerar o desenvolvimento de competências além dos conhecimentos adquiridos ao longo do curso, no âmbito construtivista. As notas finais, portanto, representam uma combinação de desempenhos agrupados sinergicamente pelo CHA, ancorados em uma perspectiva multidimensional.

\begin{tabular}{|c|c|c|c|c|c|}
\hline Elementos & Focos & $\begin{array}{c}\text { Valor das } \\
\text { Avaliações } \\
\end{array}$ & $\begin{array}{l}\text { Peso } \\
(\%)\end{array}$ & Instrumento & Forma \\
\hline \multirow{6}{*}{ Conhecimento } & Compreensão PBL & 50 & \multirow{3}{*}{30} & \multirow{3}{*}{$\begin{array}{c}\text { Prova em sala de } \\
\text { aula }\end{array}$} & \multirow{3}{*}{ Individual } \\
\hline & $\begin{array}{l}\text { Compreensão do problema } \\
\text { escolhido pelo grupo }\end{array}$ & 20 & & & \\
\hline & $\begin{array}{l}\text { Compreensão de conceitos da } \\
\text { disciplina }\end{array}$ & 30 & & & \\
\hline & Socialização do projeto parcial & 100 & 10 & $\begin{array}{c}\text { Relatório entregue } \\
\text { e apresentado em } \\
\text { sala }\end{array}$ & Grupo \\
\hline & Socialização do projeto final & 100 & 20 & Relatório entregue & Grupo \\
\hline & $\begin{array}{l}\text { Apresentação oral na } \\
\text { socialização do projeto final }\end{array}$ & 100 & 30 & $\begin{array}{c}\text { Apresentação e } \\
\text { discussão na sala } \\
\text { de aula do projeto } \\
\text { final }\end{array}$ & Grupo \\
\hline Habilidades & $\begin{array}{l}\text { Trabalho em equipe, } \\
\text { criatividade, visão sistêmica, } \\
\text { comunicação, planejamento, } \\
\text { integração com a empresa, } \\
\text { integração com outras } \\
\text { disciplinas, desenvolvimento } \\
\text { de projeto, análise crítica, } \\
\text { solução de problema, } \\
\text { autoavaliação, estudo } \\
\text { independente e trabalho } \\
\text { autorregulado. }\end{array}$ & \multirow[t]{3}{*}{100} & \multirow[t]{2}{*}{10} & \multirow[t]{2}{*}{$\begin{array}{l}\text { Autoavaliação e } \\
\text { Avaliação pelos } \\
\text { pares }\end{array}$} & \multirow[t]{2}{*}{ Individual } \\
\hline Atitudes & $\begin{array}{l}\text { Comprometimento, ética, } \\
\text { pró-atividade, empatia, } \\
\text { flexibilidade, interesse, } \\
\text { curiosidade, experiência } \\
\text { profissional, colaboração, } \\
\text { respeito pelas opiniões dos } \\
\text { outros, e liderança }\end{array}$ & & & & \\
\hline \multicolumn{2}{|r|}{ Total } & & 100 & & \\
\hline
\end{tabular}

Quadro 3. Composição dos quesitos para avaliar o desempenho dos alunos

Fonte: Elaboração Própria

Tendo em vista a perspectiva da questão de pesquisa, a análise foi desenvolvida com dois focos: (i) qual o nível de desempenho da classe como um todo, na perspectiva de que conhecimento, habilidade e atitudes devem ser tratados de forma aditiva, preservando a visão tradicional das demais disciplinas, e proporcionando possibilidade de feedback segmentado para os alunos; e (ii) qual a relação entre os vários desempenhos dos elementos do CHA, em que a preocupação fundamental é a avaliação total.

O primeiro foco, ou seja, o nível de desempenho da classe foi tratado por meio da técnica de análise de conglomerado hierárquico, utilizando a distância quadrática euclidiana e o método Between Group, o que resultou na formação de 3 clusters. Pelo teste da análise de variância ANOVA, com 5\% de nível de significância, verifica-se 
que todas as variáveis contribuíram para formação dos clusters, pois apresentaram valores de Sig. menor ou igual a 0,001. Assim obteve-se a seguinte composição, denominação e características para os 3 clusters:

Cluster 01: baixo desempenho por ausência de participação do discente nas avaliações

É formado por cinco discentes, sendo que destes, três (A1, A14 e A38) não realizaram a apresentação de socialização dos resultados encontrados e elencados no relatório final. Observa-se, ainda, que os integrantes A1 e A14 também obtiveram a pior nota na participação em sala de aula, pois ambos estavam ausentes em $25 \%$ das aulas. No grupo conhecimento, a pior média foi de 5,2 do aluno A1, sendo que este quesito foi composto pela prova, pelas socializações e pelos relatórios (parcial e final). Estes alunos estão entre os cinco discentes com menores médias finais na disciplina, sendo 5,1, 5,6 e 5,4, respectivamente.

Os demais alunos deste cluster (A17 e A32) não realizaram a autoavaliação e nem a avaliação pelos pares. Fato este que acarretou na obtenção de médias inferiores em relação aos demais alunos no conjunto das avaliações que mensuram as habilidades e as atitudes, com valores entre 3,8 e 4,4, nestas avaliações.

Cluster 02: baixo desempenho, mesmo participando de todo processo avaliativo

Os estudantes deste cluster são todos os integrantes do grupo 1 (seis discentes). Este recebeu destaque pelo baixo rendimento de seus integrantes, pois foi o grupo com a menor nota $(4,5)$ na apresentação do relatório final. As notas mais baixas da participação em sala de aula foram as dos estudantes A7 e A28. Os integrantes do grupo 1 , estão entre os dez discentes com menores médias no quesito conhecimento e, consequentemente, na média final da disciplina.

Cluster 03: bom e ótimo desempenho no processo avaliativo

Este cluster é composto por 27 discentes, sendo eles os integrantes dos grupos 2, 4, 5, 6 e 7 que realizaram as seguintes avaliações: socialização e entrega do relatório final do projeto com a solução do problema, autoavaliação, avaliação pelos pares, além de terem participado efetivamente da disciplina. Observa-se que neste cluster a menor média foi de 5,9 e a maior de 7,6 e dos 27 alunos que compõem o cluster, 26 desenvolveram melhor as atitudes, depois as habilidades e, por último, o conhecimento; apenas o integrante A26 trabalhou mais os conhecimentos, depois as atitudes e por fim as habilidades do contador e/ou do atuário.

Por sua vez, o segundo foco da análise levou em conta a análise das notas e seu relacionamento, conforme evidenciado na Tabela 1.

Tabela 1. Matriz de correlação entre as notas obtidas nos instrumentos avaliativos

\begin{tabular}{lcccccc}
\hline & $\begin{array}{c}\text { Relatório e } \\
\text { Socialização } \\
\text { do Projeto } \\
\text { (Parcial) }\end{array}$ & $\begin{array}{c}\text { Socialização } \\
\text { do Projeto } \\
\text { (Final) }\end{array}$ & $\begin{array}{c}\text { Relatório } \\
\text { Final }\end{array}$ & $\begin{array}{c}\text { Média da } \\
\text { Autoavaliação } \\
\text { e da Avaliação } \\
\text { pelos pares } \\
\text { Atitude }\end{array}$ & $\begin{array}{c}\text { Média da } \\
\text { Autoavaliação } \\
\text { e da Avaliação } \\
\text { pelo pares } \\
\text { Habilidade }\end{array}$ & $\begin{array}{c}\text { Prova } \\
\text { Escrita }\end{array}$ \\
\hline $\begin{array}{l}\text { Relatório e Socialização do } \\
\text { Projeto (Parcial) }\end{array}$ & 1 & $-0,317$ & $-0,411^{*}$ & 0,211 & 0,218 & 0,079 \\
$\begin{array}{l}\text { Socialização do Projeto } \\
\text { (Final) }\end{array}$ & $-0,317$ & 1 & $-0,042$ & $0,425^{* *}$ & $0,341^{*}$ & 0,303 \\
$\begin{array}{l}\text { Relatório Final } \\
\text { Média da Autoavaliação e } \\
\text { da Avaliação pelos pares }\end{array}$ & $-0,411^{*}$ & $-0,042$ & 1 & $-0,004$ & 0,193 & $-0,001$ \\
$\begin{array}{l}\text { Atitudes } \\
\text { Média da Autoavaliação e } \\
\text { da Avaliação pelos pares }\end{array}$ & 0,211 & $0,425^{* *}$ & $-0,004$ & 1 & $0,781^{* *}$ & 0,232 \\
$\begin{array}{l}\text { Habilidades } \\
\text { Prova Escrita }\end{array}$ & 0,218 & $0,341^{*}$ & 0,193 & $0,781^{* *}$ & 1 & 0,171 \\
\hline
\end{tabular}

Fonte: Elaboração Própria

No tocante ao segundo foco, referente à relação entre os elementos utilizados para captar o CHA, observase que entre os cinco instrumentos avaliativos as principais correlações identificadas foram as expressas na Tabela 2. 
Tabela 2. Correlação entre os elementos do CHA

\begin{tabular}{lllc}
\hline \multicolumn{2}{c}{ Correlação } & $\begin{array}{c}\text { Índice de } \\
\text { significância }\end{array}$ \\
\hline $\mathbf{1}$ & Socialização do Projeto (Final) & Relatório e Socialização do Projeto (Parcial) & $94,8 \%$ \\
$\mathbf{2}$ & Relatório Final & Relatório e Socialização do Projeto (Parcial) & $99,0 \%$ \\
$\mathbf{3}$ & $\begin{array}{l}\text { Média da Autoavaliação e da Avaliação pelos } \\
\text { pares Atitudes }\end{array}$ & Socialização do Projeto (Final) & $99,2 \%$ \\
$\mathbf{4}$ & $\begin{array}{l}\text { Média da Autoavaliação e da Avaliação pelos } \\
\text { pares Habilidades }\end{array}$ & Socialização do Projeto (Final) & $96,4 \%$ \\
$\mathbf{5}$ & $\begin{array}{l}\text { Média da Autoavaliação e da Avaliação pelos } \\
\text { pares Atitudes }\end{array}$ & $\begin{array}{l}\text { Média da Autoavaliação e da Avaliação pelos } \\
\text { pares Habilidades }\end{array}$ & $99,0 \%$ \\
\hline
\end{tabular}

Fonte: Elaboração Própria

O significado expresso na correlação 1 leva os docentes a acentuar a importância de proporcionar ao grupo a condição de começar bem o desenvolvimento do trabalho, pois se espera que quem se desempenhar bem na socialização parcial do projeto também o realizará no projeto final. Dada a condição de tempo dos alunos, essa percepção valoriza a existência de membro do grupo que possa liderar o processo e disponibilizar a organização na qual o trabalho possa ser desenvolvido. Em decorrência disso, ações podem ser pensadas tanto no que se refere a ajustar o melhor momento para a socialização do projeto como também apoios para que os alunos desenvolvam a socialização de maneira mais consistente, como por exemplo, apoio por meio de aulas extras presenciais ou salas virtuais.

Na correlação 2, como decorrência do elemento anterior, seria de se esperar que o relatório referente à socialização também tivesse associação com a socialização parcial do projeto. Os comentários anteriores também são válidos aqui. Já na associação 3, considerando que os alunos não tinham conhecimento da nota do projeto final quando fizeram a autoavaliação e a avaliação pelos pares, de alguma forma, as notas expressam o conforto e desconforto com o tema. Considerando, também, que os discentes não estão acostumados a fazer esse tipo de avaliação, as respostas proporcionam uma relevante informação sobre o comportamento e o desempenho do grupo. Em outras palavras, o desempenho grupal em termos de produto final e as atitudes foram consistentes com as notas dos demais instrumentos avaliativos, corroborando com as pesquisas de Araújo e Arantes (2009), Ribeiro (2010) e Ribeiro e Escrivão Filho (2011).

Os achados da correlação 4 foram análogos ao item anterior, e corroboram com a literatura, tais como: Araújo e Arantes (2009), Ribeiro (2010) e Ribeiro e Escrivão Filho (2011). A correlação 5 representa que, além da consistência de raciocínio, é relevante investigar a forma como os alunos desenvolveram a autoavaliação e avaliação pelos pares. De qualquer forma, a correlação entre atitudes e habilidades foi constatada, trazendo impacto sobre o resultado dos grupos.

\section{CONSIDERAÇÕES FINAIS}

O presente artigo buscou interpretar a nota e a aprovação dos alunos ao final do semestre na avaliação de uma disciplina baseada no PBL e observou-se que a entrega ao aluno de uma nota sintetizadora do seu desempenho não proporciona a ele uma visão ampla dos fatores desenvolvidos pelos mesmos nas atividades semestrais. Isso acontece porque, diferentemente do método tradicional em que a avaliação pode acontecer por meio de um único instrumento ao final do semestre, nesta disciplina a abordagem foi diferenciada, pois cada atividade desenvolvida pelo aluno foi considerada como uma avaliação.

Observou-se que, embora exista certa homogeneidade etária na turma, tendo em vista que a maior parte dos alunos possui no máximo 25 anos, o estudo detalhado do processo avaliativo evidenciou que cada aluno incorporou à sua nota, àquela que foi necessária para aprovação ou não do discente, elementos bem diferenciados.

Deste cenário, surgem três clusters que evidenciam quais são os elementos educacionais mais desenvolvidos na disciplina pelos docentes. Os cinco alunos com baixo desempenho devido a não realização de uma ou mais etapa do processo avaliativo estão alocados no cluster 1 e representam $13 \%$ da turma. Já $16 \%$ do total de alunos aprovados na disciplina apresentaram baixo rendimento mesmo realizando todas as avaliações 
e foram posicionados no cluster 2. Por outro lado, os grupos que trabalharam de forma cooperativa, planejada e com comprometimento ficaram elencados no cluster 3 , contemplando $71 \%$ dos discentes e, principalmente, aqueles que apresentaram maior número de elementos incorporados à nota de aprovação na disciplina, ou seja, que apresentaram bom ou ótimo desempenho nas avaliações. Ressalta-se que nenhum aluno deixou de ser aprovado na disciplina.

Ao avaliar os processos cognitivos, ou seja, a aquisição de conhecimentos, de habilidades e de atitudes dos alunos oriundos da inserção e interação do indivíduo em uma situação de resolução de problema real do mercado de trabalho, observou-se que as atitudes foram as mais desenvolvidas pela turma, com média de 8,0. Este fato está vinculado à atividade desenvolvida em grupo durante todo o semestre, pois a atitude é a expressão da disposição e/ou à intenção que influencia a pessoa a adotar determinado comportamento em relação às demais pessoas, aos objetos e a situação no meio social (BRANDÃO, 2009). Este comportamento foi avaliado pelos docentes no tocante a participação em sala e junto à turma. Destaca-se nesta perspectiva que os alunos ao se autoavaliarem a média foi aferida em 7,9 e ao avaliarem seus colegas $(8,1)$ valorizaram o respeito à opinião dos outros, a ética, a empatia, o interesse e a colaboração. Constatou-se que a maior parte dos instrumentos avaliativos contempla o quesito conhecimento correspondendo a $90 \%$ da nota final da disciplina e os elementos habilidade e atitudes, somaram apenas $10 \%$.

Dada a natureza exploratória, a quantidade de alunos e a escassez de referencial que permita estruturar o construto de maneira mais consistente, a análise do nível de significância serve para alertar os pesquisadores da potencialidade de ações que possam aperfeiçoar o processo de aprendizagem de forma a contemplar suas múltiplas dimensões. De qualquer forma algumas correlações foram identificadas, tais como a socialização parcial e final, a socialização parcial e o relatório final, a auto avaliação e o projeto final e mesmo auto avaliação e avaliação pelos pares das habilidades e atitudes. Esse conjunto permite refletir sobre a adequação do modelo considerado, bem como ajustá-lo para utilização da metodologia em outros momentos e ambientes.

Pelo fato do PBL não ser uma iniciativa institucional e constituir a primeira experiência destes alunos, nota-se que não foram todos os alunos que detinham, ao final da disciplina, o discernimento para elencar os elementos que os levaram a serem aprovados. Porém, pode-se concluir que a disciplina atingiu seu objetivo de integrar ensino, pesquisa e prática, pois segundo Enemarl e Kjaersdam (2009, p. 20-21), “[...] o sucesso de um sistema educacional depende de uma forte interação entre ensino, pesquisa e prática profissional". Este pode ser observado em um dos relatos avaliativos realizado por um dos discentes sobre a disciplina, ao afirmar que a mesma “[...] permite o exercício da aplicação da teoria, à prática vivenciada nas empresas. Mas também é uma disciplina que fornece instrumentos ao pesquisador. Integra estes objetivos, estimula o aluno a desenvolver a análise crítica necessária para ser um profissional mais preparado".

Como sugestões de continuidade da pesquisa, recomenda-se a replicação da mesma utilizando maiores pesos na avaliação de habilidades e atitudes e menos em conhecimentos. Também é possível verificar se os resultados se comportam de maneiras diferentes quando o modelo for aplicado a disciplinas obrigatórias.

\section{REFERÊNCIAS}

ANDERSON, L. W.; KRATHWOHL, D. R. Taxonomy for learning, teaching, and assessing: a revision of Bloom's taxonomy of educational objectives. New York: Addison Wesley, 2000.

ARAÚJO, U. F.; ARANTES, V. A. Comunidade, conhecimento e resolução de problemas: o projeto acadêmico da USP Leste. In.: ARAÚJO, U. F.; SASTRE, G. (Orgs.). Aprendizagem baseada em problemas no ensino superior. São Paulo: Summus, 2009, pp. 101-122.

BLOOM, B. S; ENGELHART, M. D.; FURST, E. J.; HILL, W. H.; KRATHWOHL, D. R. Taxonomia de objetivos educacionais: domínio cognitivo. São Paulo: Pioneira, 1983.

BRANDÃO, H. P. Aprendizagem, contexto, competência e desempenho: um estudo multinível. 363 f., 2009. Tese (Doutorado em Psicologia Social, do Trabalho e das Organizações). Instituto de Psicologia, Universidade de Brasília, Brasília-DF, 2009. 
IN ENGINEERING EDUCATION SYMPOSIUM, University of Melbourne, 2009, p. 1-9. Anais... Palm Cove, QLD: REES

CHAVES, J. F.; BAKER, C. M.; CHAVES, J. A.; FISHER, M. L. F. Self, peer, and tutor assessments of MSN competencies using the PBL-Evaluator. Journal of Nursing Education, v. 45, n.1, 2006.

COUGHLAN, P.; COGHLAN, D. Action research: action research for operations management, International Journal of Operations \& Production Management, v.22, n.2, p. 220-240, 2002.

DALRYMPLE, K. R; WONG, S.; ROSENBLUM, A.; WUENSCHELL, C.; PAINE, M., \& SHULER, C. F. PBL core skills faculty development workshop 3: understanding PBL process assessment and feedback via scenario-based discussions, observation, and role-play. Journal of dental education, v. 71, n. 12, p. 1561-1573, 2007.

DES MARCHAIS, J. E. A Delphi technique to identify and evaluate criteria for construction of PBL problems. Medical Education, v. 33, n. 7, p. 504-508, 1999.

DESAULNIERS, J. B. R. Formação, competência e cidadania. Educação \& Sociedade, v. 18, n. 6, p. 51-63, dez., 1997.

DUCH, B. J. Writing problems for deeper understanding. In.: DUCH, B. J.; GROH, S. E.; ALLEN, D. E. The power of problem-based learning: a practical "how to" for teaching undergraduate courses in any discipline. Virginia: Stylus Publishing, 2001, pp. 47-53.

ENERMARK, S.; KJAERSDAM, F. AABP na teoria e na prática: a experiência de Aalborg na inovação do projeto no ensino universitário. In.: ARAÚJO, U. F.; SASTRE, G. (Orgs.). Aprendizagem baseada em problemas no ensino superior. São Paulo: Summus, 2009, pp. 17-42.

FERRAZ, A. P. C. M.; BELHOT, R. V. Taxonomia de Bloom: revisão teórica e apresentação das adequações do instrumento para definição de objetivos instrucionais. Gestão da Produção, São Carlos, v. 17, n. 2, p. 421-431, 2010 .

FREZATTI, F.; ROCHA, W.; NASCIMENTO, A. R.; JUNQUEIRA, E. Controle gerencial: uma abordagem da contabilidade gerencial no contexto econômico, comportamental e sociológico. São Paulo: Atlas, 2009.

FREZATTI, F.; SILVA, S. C. Prática versus incerteza: como gerenciar o estudante nessa tensão na implementação de disciplina sob o prisma do método pbl?.Revista Universo Contábil, v. 10, n. 1, p. 28-46, 2014.

LE BOTERF, G. Desenvolvendo a competência dos profissionais. 3 ed. Porto Alegre: Artmed, 2000.

MACDONALD, R.; SAVIN-BADEN, M. A briefing on assessment in problem-based learning. LTSN Generic Centre, Series n. 13, 2004.

MANAF, N. A. A.; ISHAK, Z.; HUSSIN, W. N. W. Application of problem based learning (PBL) in a course on financial accounting principles. Malaysian Journal of Learning and Instruction, n. 8, p. 21-47, 2011.

MARCONI, M. A.; LAKATOS, E. M. Fundamentos de metodologia científica. 5.ed. São Paulo: Atlas, 2003.

MARKS-MARAN, D.; GAIL THOMAS, B. Assessment and evaluation in problem based learning. In.: GLEN, S.; WILKIE, K. Problem-based learning in nursing: a new model for a new context?. Palgrave Macmillan, 2000, pp. 127-150.

Martins, D. B.; Espejo, M. M. S. B. Problem Based Learning - PBL no ensino de contabilidade: guia orientativo para professores e estudantes da nova geração. São Paulo: Atlas, 2015.

METTETAL, G. Classroom action research as problem-based learning. In.: LEVIN, B. B. Energizing teacher education and professional development with problem-based learning, 2001, pp.108-120. 
PORTON, R. A. B.; BEUREN, I. M. Formulação de hipóteses e caracterização de variáveis em pesquisa Contábil. In: BEUREN, I. M. (Org.). Como elaborar trabalhos monográficos em contabilidade. 3 ed. São Paulo: Atlas, 2008.

RIBEIRO, L. R. C. Aprendizagem baseada em problemas (PBL): uma experiência no ensino superior. São Carlos: UduFSCAR, 2010.

RIBEIRO, L. R.C; ESCRIVÃO FILHO, E. Avaliação formativa no ensino superior: um estudo de caso. Acta Scientiarum. Human and Social Sciences, v. 33, n. 1, p. 45-54, 2011.

RODRIGUES, E. A.; ARAÚJO, A. M. P. O ensino da contabilidade: aplicação do método PBL nas disciplinas de contabilidade em uma instituição de ensino superior particular. Revista de Educação, v. 10, n. 10, 2007.

ROSA, A. P.; CORTIVO, L. D.; GODOI, C. K. Competências profissionais: uma análise da produção científica brasileira de 1999 a 2004. Revista de Negócios, v. 11, n. 1, p.77-88, jan./mar., 2006.

SAVERY, J. R. Overview of problem-based learning: definitions and distinctions. Interdisciplinary Journal of Problem-based Learning. v. 1, n. 1, p. 9-20, 2006.

SCHMIDT, H. G. Problem-based learning: rationale and descriptions. Medical Education, n. 17, p. 11-16, 1983.

SILVA, A. C. R. Metodologia da pesquisa aplicada à contabilidade. 2.ed. São Paulo: Atlas, 2008.

SIQUEIRA-BATISTA, R.; SIQUEIRA-BATISTA, R. Anéis da serpente: a aprendizagem baseada em problemas e as sociedades de controle. Ciência \& Saúde Coletiva, v. 14, n. 4, p. 1183-1192, 2009.

Siqueira, J. R. M., Siqueira-Batista, R. S., Morch, R. B., \& Siqueira-Batista, R. S. Aprendizagem baseada em problemas: o que os médicos podem ensinar aos contadores. Contabilidade Vista \& Revista, v. 20, n. 3, p. 101-125, 2009.

SOARES, Mara A. ; ARAUJO, A. M. P. ; LEAL, E. A. . Evidências Empíricas da Aplicação do Método ProblemBased Learning (PBL) na disciplina de Contabilidade Intermediária do Curso de Ciências Contábeis. In: COIMBRA, Camila Lima. (Org.). Didática para o ensino nas áreas de administração e ciências contábeis. São Paulo: Atlas, 2012, v. 1, p. 74-92.

THERRIEN, J.; LOIOLA, F. A. Experiência e competência no ensino: pistas de reflexões sobre a natureza do saber-ensinar na perspectiva da ergonomia do trabalho docente. Educação \& Sociedade, ano XXII, 74, abr., 2001 .

UNGARETTI, T.; Thompson, K.; Miller, A.; Peterson, T. Problem Based Learning: Lessons from Medical Education and Challenges for Management Education. Academy of Management Learning \& Education, v. 14, n. 2, p.173-186, 2015.

VASCONCELOS, A. F.; CAVALCANTE, P. R. N.; MONTE, P. A. Uma análise das competências dos professores de ciências contábeis a partir do envolvimento em atividades de pesquisa e extensão. In.: ENCONTRO DA ANPAD, XXXV, Rio de Janeiro, 4 a 7 de setembro, 2011. Anais...

WOODS, D. R Helping your students gain the most from PBL. In.: ASIA-PACIFIC CONFERENCE ON PBL, $2^{\text {nd }}$, Singapore, 4 to 7 December, 2000. Anais...

WOODS, D. R. Preparing for PBL. 3th ed., Hamilton, ON, Canada: McMaster University, March, 2006.

WRIGHT, S. L.; SMITH, M.; DUNCAN, M. Student perceptions and experiences of problem- based learning in first year undergraduate sports therapy. In.: DAVIES, J.; GRAAFF, E.; KOLMOS, A. (Eds.). PBL across the disciplines: research into best practice. Aalborg University Press, 2011, pp. 92-105.

YIN, R. K. Estudo de caso: planejamento e métodos. Porto Alegre: Bookman, 2001.. 